\title{
SOME PROPERTIES OF GRAND SOBOLEV-MORREY SPACES WITH DOMINANT MIXED DERIVATIVES
}

\author{
Alik M. Najafov And Sain T. Alekberli
}

Abstract. In this paper we construct a grand Sobolev-Morrey spaces with dominant mixed derivatives, and by means of integral representation we study differential and differential-difference properties of functions from this spaces.

Mathematics subject classification (2010): 46E35, 46E30, $26 \mathrm{D} 15$.

Keywords and phrases: Grand Sobolev-Morrey spaces with dominant mixed derivatives, integral representation, embedding theorem, Hölder condition.

\section{REFERENCES}

[1] T. I. Amanov, Representation and embedding theorems for function spaces SB, Trudy Mat. Inst. Steklov., 77, Nauka, 1965, pp. 5-34.

[2] O. V. BESOV, V. P. IL'YIN AND S. M. NIKOLS KII, Integral representations of functions and embeddings theorems, M. Nauka, 1996, 480 pp.

[3] A. D. DJABRAILOV, Families of spaces of function whose mixed derivatives satisfy a multiple-integral Hölder condition, Trudy Mat.Inst. Steklov, 1972,v.117, pp. 139-158 (in Russian).

[4] T. IWANIEC AND C. SBordone, On the integrability of the Jacobian under minimal hypotheses, Arch. Ration. Mech. Anal., 119, 1992, pp. 129-143.

[5] A. Fiorenza AND C. E. KARADZHOV, Grand and small Lebesgue spaces and their analogs, J. Anal. Appl., vol. (23)(4) (2004), pp. 657-681.

[6] V. KoKILASHVILI, The Riemann boundary value problem for analytic functions in the frame of grand $L^{p}$ spaces, Bull. Georgian Nat. Acad. Sci., vol. 4, No 1, 2010, pp. 5-7.

[7] V. Kokilashvili, A. Meskhi And H. Rafeiro, Estimates for nondivergence elliptic equations with VMO coefficients in generalized grand Morrey spaces, Comp. Var. Ellip. Equations, 8 (59), 2014, pp. 1169-1184.

[8] V. KokilashVili AND A.MeskHI, Trace inequalities for fractional integrals in grand Lebesgue spaces, Studia Math., 210(2), 2012, pp. 159-176.

[9] A. Meskhi, Maximal functions, potentials and singular integrals in grand Morrey spaces, Comp. Var. Ellip. Equations, 2011, DOI: 10, 1080/17476933: 2010, 534793.

[10] Y.Mizuta, T.OHno, Trudingers exponential integrability for Riesz potensials of function in generalized grand Morrey spaces, J. Math. Anal. Appl., 420(1)(2014), pp. 268-278.

[11] A. M. NADZHAFOV, Embedding theorems in the Sobolev-Morrey type spaces $S_{p, a, \varkappa, \tau}^{l} W(G)$ with dominant mixed derivatives, Sib. Math. J., (47)(3), 2006, pp. 505-516.

[12] A. M. NAJAFOV, Some properties of function from the intersection of Besov-Morrey type spaces with dominant mixed derivatives, Proc. of A. Ramzmadze Math. Inst., 2005, v.139, pp. 71-82.

[13] A. M. NAJAFOV AND N. R. Rustamova, Some differential properties of anisotropic grand SobolevMorrey spaces, Trans. of A. Razmadze Mathematical Institute Vol. 172, Issue 1, 2018, pp. 82-89.

[14] A. M. NAJAFOV, The differential properties of functions from Sobolev-Morrey type spaces of fractional order, Journal of Mathematical Recearch, v.7, no 3, 2015, pp. 1-10.

[15] S. M. NiKOLSKII, Functions with dominant mixed derivative satisfying a multiple Hölder condition, Sib.M.Jour., 1963, v.4(6), pp. 1342-1364.

[16] H. RAFEIRO, A note on boundedness of operators in grand Morrey spaces, Arxiv: 1109, 2550 v1 [math. FA], 2011. 
[17] S. G. SAMKo AND S. M. UMARKhADZhIEv, On Iwaniec - Sbordone spaces on sets which may have infinite measure, Azerb. Jour. Math. 2011, vol. 1, No 1, pp. 67-84, v.1, no 2, pp. 143-144.

[18] C. Sbordone, Grand Sobolev spaces and their applications to variational problems, Le Mathematiche, vol. LI, 1996, Fasc. II, pp. 335-347.

[19] S. M. UMARKHADZHIEV, The boundedness of the Riesz potential operator from generalized grand Lebesgue spaces to generalized grand Morrey spaces, Operator Theory: Advances and Applications, Basel, 2014, vol.242, pp. 363-373. 